\title{
A social work study to investigate the relationships between women's personal characteristics and employment status
}

\author{
Shahram Basity $^{\mathrm{a}^{*} \text {, Mohammad Reza Iravani }}{ }^{\mathrm{b}}$, Zahra Ghassabi ${ }^{\mathrm{c}}$, Faezeh Taghipour ${ }^{\mathrm{d}}$ and Hajar \\ Jannesari $^{\mathrm{e}}$
}

${ }^{a} \mathrm{PhD}$, Department of Social Science, Payame Noor University/PO BOX 19395-3697 Tehran, Iran

${ }^{b}$ Assistant Professor, Department of Social Work, Islamic Azad University Khomeinishahr Branch, Daneshjou Blvd, Iran

${ }^{c}$ Master of Demography

${ }^{d}$ Assistant Professor, Department of Cultural Management Khorasgan (Isfahan) Branch, Islamic Azad University, Isfahan, Iran

${ }^{e}$ MS Student, Counseling Department, Islamic Azad University of Khomeinishahr, Khomeinishahr Branch, Daneshjou Blvd, Iran

CHRONICLE

Article history:

Received October 14, 2012

Received in revised format

24 December 2012

Accepted 5 January 2013

Available online

January 72013

Keywords:

Women

Employment

Social work study

\begin{abstract}
A B S T R A C T
Women play important role on building a sustainable family oriented society; they could also contribute to society by contributing to labor market. However, women's personal characteristics such as educational background, years of experience, etc. could impact their future occupations. In this paper, we study the impact of various factors on women's job status. The measurement tools for social factors of employment in this research is a questionnaire consists of 32 questions. The study measures the reflection of repliers to different social factors including social position, popularity, socialize, social manners, self-reliance, speech abilities, responsibility, etc. Data were gathered from a sample of 300 people using random sampling and analyzed using descriptive mono factor statistics, Spearman correlation, Kramer correlation coefficient, Chi-square, regression and path analysis. The validity of questionnaire is tested by using Cronbach alpha (\%75). The results indicate that there are some meaningful relationships between woman's educational level, age, residency status, socialization capability, urbanity, skill \& ability and their employment. The study, however, does not find any relationship between marital status and number of children and woman's income with employment.
\end{abstract}

\section{Introduction}

Nowadays, Women have become precious assets for developing economy since they could help family income by contributing to their society. Women play important role on building a sustainable family oriented society; they could also contribute to society by contributing to labor market. However, women's personal characteristics such as educational background, years of experience, etc. could impact their future occupations. They could also act as entrepreneurs who are considered as big

*Corresponding author. Tel:+ 989125253141

E-mail addresses: shahram.basity@gmail.com (S.Basity)

(C) 2013 Growing Science Ltd. All rights reserved. doi: 10.5267/j.msl.2013.01.007 
potentials for developing economy in any countries by providing new job opportunities and help economy boost.

Zakeri Nasrabadi et al. (2012) investigated the relationship between three entrepreneurship opportunities including universities, technical and vocational centers and women. They reported that technical and vocational centers were, in fact, the best place for training basic or recent advances in technological skills through short term or long term planning. The survey also indicated that women could be considered as a good source of job creation.

Zarandi (2012) investigated different factors influencing women's employment in Tehran SME from those women's perspectives. They used Lerner's model, which is more comprehensive than the other similar models and carried out through distribution of some questionnaires among a statistical population including 384 women living in the city of Tehran. They concluded that economic elements (as an environmental factor), achievement requirement (as an individual factor) and encouragement (as an organizational factors) respectively could influence women's employment.

Iravani and Razi (2012) discussed job discrimination against women and explained that for many decades, women were discriminated against men for paying less in equal job positions. They investigated women's position in terms of two perspectives of economic and education for the people who live in a city of Esfahan, Iran. They designed a questionnaire and distribute among 880 people who were randomly chosen from a population of 441782 residences. The result of their study confirmed that Iranian women were placed well and job placement of the Iranian women was low. They also concluded that Iranian women were quite forward and there would be definite reasons for drop out. Mansouri (2012), in other study, investigated on convention on the elimination of all forms of discrimination against women in Iran.

Tajbakhsh et al. (2013) selected a sample from all female students who were enrolled in educational studies in Shiraz university, Iran and using Pearson correlation test, they measured the relationship between seven mentioned items with respect for women. They reported that except one case, participation and community involvement, all other factors substantially increase respect for women.

Keramati et al. (2013) discussed on relative importance of organizational commitment as part of business development especially in educational system. They investigated the relationship between six personal characteristics of employees of Azad University in province of Arak, Iran. They investigated on six independent variables including age, gender, educational background, marital status, job experience and salary with organization commitment. They reported that marital status was the most influential factor on organizational commitment followed by educational background and job experience. They also concluded that those employees who could get more experience and maintain a good educational background would more likely to stay with a firm than young employees could.

Iravani et al. (2012b) performed a survey to study the impact of stress among people with different job titles and ages in a hydropower unit located in city of Esfahan, Iran. They reported that there were no meaning differences among people with different job titles but people in various age groups maintained different level of stress.

Iravani et al. (2012a) measured the effect of stress among people with different gender and marital status in the same plant and concluded that gender had no meaningful effect on creating stress among employees who worked for this hydro plant except difficulty of job conditions. They also reported that stress posed from management team had various impacts on employees with different marital status but there were no meaningful differences between married and single couples in terms of other factors posing stress such as unsuitable working conditions, fear of job stability or difficulty of job conditions. 
Ahmadi et al. (2012) investigated the relationship between job performance and employees' mental health in one of Iranian natural gas refinery located in city of Jam, Iran. They reported that there was a significant relationship between employees' job performance and mental health and any increase in mental health aspects could increase job performance. However, there was not any relationship between employees' job performance and their gender, nor was any difference on mental health status between male and female staff. They concluded that low mental health level among employees could reduce their performance and we should decrease the negative consequences resulted from the lack of mental health in workplaces.

Khodaei Valahzaghard et al. (2012) investigated the impacts of related services to support employee to reach job satisfaction and employee activities in one of Iranian banks called Mellat bank based on 276 random samples. Their results indicated that employees were relatively satisfied from the benefit package of the bank and they were relatively happy on working for such organization.

\section{The proposed study}

In this paper, we study the impact of various factors on women's job status. The measurement tools for social factors of employment in this research is a questionnaire consists of 32 questions. The study measures the reflection of repliers to different social factors including social position, popularity, socialize, social manners, self-reliance, speech abilities, responsibility, etc. Data were gathered from a sample of 300 people using random sampling and analyzed using descriptive mono factor statistics, Spearman correlation, Keramer correlation coefficient, Chi-square, regression and path analysis. The validity of questionnaire is tested by using Cronbach alpha (\%75).

\section{The results}

In this section, we present details of nine hypotheses associated with the proposed study of this paper.

\subsection{The first hypothesis: Relationship between level of education and employment}

The first hypothesis considers the relationship between level of education and job status. The null hypothesis for this hypothesis is that there is no relationship between these two items. Table 1 shows statistics associated with the level of education of our sample study.

Table 1

Educational background and employment status

\begin{tabular}{lcccc}
\hline & & Employment & Total \\
\hline Years of education & Low & Average & High & 6 \\
\hline Less than 12 years & 0 & 4 & 2 & 25 \\
12 years & 2 & 8 & 42 & 76 \\
14 years & 2 & 32 & 117 & 174 \\
16 years & 6 & 51 & 10 & 19 \\
18 years and higher & 1 & 8 & 186 & 300 \\
\hline Total & 11 & 103 & & \\
\hline
\end{tabular}

Kramer correlation coefficient has been calculated as 0.31 with Sig. $=0.000$, which means the null hypothesis, no relationship between educational background and employment status, has been rejected and we can conclude that educational background impacts on job status, positively.

\subsection{The second hypothesis: Relationship between age and employment}

The second hypothesis considers the relationship between women's age and employment. The null hypothesis for this hypothesis is that there is no relationship between these two items and Table 2 demonstrates statistics associated with this study. 
Table 2

Women's age and employment status

\begin{tabular}{lcccc}
\hline & \multicolumn{5}{c}{ Employment } \\
\hline Age & Low & Average & High & Total \\
\hline $29-20$ & 1 & 18 & 31 & 50 \\
$39-30$ & 5 & 47 & 89 & 141 \\
$49-40$ & 5 & 34 & 61 & 100 \\
50 and more & 0 & 4 & 5 & 9 \\
\hline Total & 11 & 103 & 186 & 300 \\
\hline
\end{tabular}

Pearson correlation coefficient has been calculated as 0.142 with Sig. $=0.009$, which means the null hypothesis, no relationship between age and employment status, has been rejected and we can conclude that age impacts on job status, positively.

\subsection{The third hypothesis: Relationship between number of children and employment}

The third hypothesis considers the relationship between the number of children women have and employment status. The null hypothesis for this hypothesis is that there is no relationship between these two items and Table 3 demonstrates statistics.

Table 3

Women's number of children and employment status

\begin{tabular}{lcccc}
\hline & \multicolumn{3}{c}{ Employment } & Total \\
\hline Number of children & Low & Average & High & 50 \\
\hline Fewer than 3 & 8 & 65 & 133 & 141 \\
3-4 children & 3 & 37 & 52 & 100 \\
5 and more children & 0 & 1 & 1 & 300 \\
\hline Total & 11 & 103 & 186 & 0 \\
\hline
\end{tabular}

Chi-Square test has been calculated as 2.38(Sig.=0.655), which is less than critical value of 9.48 when the level of significance is five percent. Therefore, we have no evidence to reject the null hypothesis, which means the null hypothesis of having no relationship between women's number of children and employment status is accepted, and we cannot conclude that children have any impact on job status.

\subsection{The fourth hypothesis: Relationship between marital status and employment}

The fourth hypothesis considers the relationship between marital status and employment. The null hypothesis for this hypothesis is that there is no relationship between these two items. Table 4 demonstrates statistics associated with the level of education of our sample study.

\section{Table 4}

Women's marital status and employment

\begin{tabular}{lcccc}
\hline & \multicolumn{3}{c}{ Employment } & Total \\
\hline Number of children & Low & Average & High & 274 \\
\hline Single & 8 & 97 & 169 & 16 \\
Married & 2 & 3 & 11 & 01 \\
Divorced & 1 & 3 & 6 & 300 \\
\hline Total & 11 & 103 & 186 & 300 \\
\hline
\end{tabular}

Chi-Square test has been calculated as 6.32(Sig.=0.176), which is less than critical value of 9.48 when the level of significance is five percent. Therefore, we have no evidence to reject the null hypothesis, which means the null hypothesis of having no relationship between women's marital status and employment status is accepted, and we cannot conclude that marital status have any impact on job status. 


\subsection{The fifth hypothesis: Relationship between living status and employment}

The fifth hypothesis considers the relationship between living status and employment. The null hypothesis for this hypothesis is that there is no relationship between these two items. Chi-Square test has been calculated as 16.94 (Sig.=0.002), which is greater than critical value of 9.48 when the level of significance is five percent. Therefore, we reject the null hypothesis and conclude that living status in terms of location and ownership influences employment, significantly.

\subsection{The sixth hypothesis: Relationship between socialization capabilities and employment}

The sixth hypothesis considers the relationship between socialization capabilities and employment. The null hypothesis for this hypothesis is that there is no relationship between these two items. ChiSquare test has been calculated as 50.36 (Sig.=0.000), which is well greater than critical value of 9.48 when the level of significance is five percent. Therefore, we reject the null hypothesis and conclude that socialization capabilities influences employment, significantly.

\subsection{The seventh hypothesis: Relationship between socialization capabilities and employment}

The seventh hypothesis considers the relationship between socialization capabilities and employment. The null hypothesis for this hypothesis is that there is no relationship between these two items. ChiSquare test has been calculated as 10.35 (Sig.=0.000), which is more than critical value of 9.48 when the level of significance is five percent. Therefore, we reject the null hypothesis and conclude that socialization capabilities influences employment, significantly.

\subsection{The eighth hypothesis: Relationship between personal skills and employment}

The eighth hypothesis considers the relationship between personal skills and employment. The null hypothesis for this hypothesis is that there is no relationship between these two items. Chi-Square test has been calculated as 10.085 (Sig.=0.000), which is above the critical value of 9.48 when the level of significance is five percent. Therefore, we reject the null hypothesis and conclude that personal skills impacts employment, significantly.

\subsection{The ninth hypothesis: Relationship between personal income and employment}

The ninth hypothesis considers the relationship between personal income and employment. The null hypothesis for this hypothesis is that there is no relationship between these two items. Pearson correlation ratio has been calculated as -0.075 (Sig. $=0.071$ ), which means the null hypothesis is accepted and we conclude that there is no meaningful relationship between these two components.

\section{Conclusion}

We have performed an empirical study to investigate the impact of different factors on women's job status. The study measured the reflection of repliers to different social factors including social position, popularity, socialize, social manners, self-reliance, speech abilities, responsibility, etc. The results have shown that there were some relationships between woman's educational level, age, residency status, socialization capability, urbanity, skill \& ability and their employment. However, we did not find any relationship between marital status and number of children and woman's income with employment.

\section{Acknowledgment}

The author would like to thank all people who participated in our survey and cordially cooperated in accomplishment of this survey. 


\section{References}

Ahmadi, P., Bakhshizadeh, A., Balouchi, H. (2012). Studying the impact of mental health on job performance of managers and staff. Management Science Letters, 2(5), 1579-1588.

Iravani, A. Iravani, M.R., Iravani, G., Khorvash, M., \& Mosavi, S.M. (2012a). A social work study on measuring the impact of gender and marital status on stress: A case study of hydro-power employees. Management Science Letters, 2(6), 2097-2102.

Iravani, A. Iravani, M.R., Iravani, G., Khorvash, M., \& Mosavi, S.M. (2012b). A social work study on measuring the impact of age and job title on stress: A case study of hydro-power employees. Management Science Letters, 2(6), 2243-2248.

Iravani, M.R., \& Razi, Z. (2012). A social work study on job placement and dropout. Management Science Letters, 2(3), 1023-1030.

Keramati, M.A., Horri, M.S., \& Afzalipoor, S.H.R. (2013). A study on effects of personal characteristics on organizational commitment. Management Science Letters, 3(1), 345-350.

Khodaei Valahzaghard, M., \& Afzali, F., \& Khodaei Valahzaghard, S. (2012). An empirical study on the effects of human resource supporting strategies on job satisfaction. Management Science Letters, 2(5), 1535-1542.

Mansouri, H. (2012). A study on convention on the elimination of all forms of discrimination against women. Management Science Letters, 2(3), 775-780.

Tajbakhsh, G.R., Iravani, M.R., Arabmomeni, A., \& Jannesari, H. (2013). A social work study on the impact of different factors on respect to women. Management Science Letters, 3(1), 291-296.

Zakeri Nasrabadi, Z., Nikbakht, A., \& Solimani Rad, A. (2012). A social work study on different entrepreneurship opportunities. Management Science Letters, 2(6), 2231-2236.

Zarandi, M. (2012). Key-Factor analysis of elements affecting women's employment in small and medium enterprises (SME) among women living in Tehran. Management Science Letters, 2(6), 2041-2048. 